\title{
Gamification in Corporate Training to Enhance Engagement: An Approach
}

\author{
https://doi.org/10.3991/ijet.v15i17.14207 \\ Saverio Iacono, Mario Vallarino, Gianni Vercelli $\left({ }^{凶}\right)$ \\ University of Genoa, Genoa, Italy \\ gianni.vercelli@unige.it
}

\begin{abstract}
Engagement in the companies' training programs is a crucial issue for their success. Every company faces the matter in different manners: some enterprises promote mandatory courses or programs; however, they may result not enough effective, due to a low level of motivation that can compromise learning and retention. Other enterprises prefer to adopt voluntary courses or programs, but in this case enrollment and completion depend on many factors: the time that workers can spend on training without compromising their main tasks; the directives of managers; the individual motivation. Another way to face corporate training may exploit gamification to enhance engagement. The authors present the design and implementation of a gamified course of office automation, developed for the employees of a large media company. Our approach attempts to go beyond the well-known triad point-badges-leaderboards, employing also a narrative, the Bartle's taxonomy of player types and the Selfdetermination theory by Deci and Ryan.
\end{abstract}

Keywords - Corporate training, gamification, engagement, e-learning, storytelling.

\section{Introduction}

Corporate training is a delicate issue, because it concerns the worker's motivation to improve his skills in order to increase individual productivity [1][2][3]. Furthermore, it also regards the time the worker can spend to carry out training [4][5][6].

Over time, a growing number of worldwide companies have adopted gamification to improve the completion performance of their training programs, applying it with results varying from case to case and leading to different levels of satisfaction [7][8].

Gamification can be defined as "The use of game elements and game-design techniques in non-game contexts" [9, p.26]. It can be used in a variety of contexts for engagement growth [10][11]. The main advantages are:

- Engagement growth

- Sense of making significant choices

- Sense of progression

- Growth of social interactions

- Creating habits [9]. 
A still poorly investigated aspect of gamification in corporate training is the application to a single online course, not mandatory in enrollment and completion, to enhance participant's engagement and therefore its completion rate [7][12].

As part of the collaboration with an important media company, Sky Italia (the Italian branch of Sky Limited, recently acquired by Comcast Corporation), the authors developed the gamification of an office automation course, called "Effective communication with PowerPoint", whose first release has been delivered at the moment of writing. In addition, a secondary goal is also to compare the results of this course, in terms of completions, with another "non-gamified" office automation course, entitled "Excel beginner and intermediate". Both courses are addressed to all Sky Italia's employees, about 5000 people.

The aim of this work is to present a novel gamification approach, called Storypowered Gamification Method (SGM), which integrate the usual triad points-badgesleaderboards with consolidated scientific theories and some design features to form a solid foundation for significantly improving the engagement of participants in a corporate online course whose attendance is not mandatory.

\section{Related Works}

Improving oneself motivation and optimizing work processes is a problem that is at the heart of any large organization context. Gamification represents a promising opportunity to enhance the outcome of employees, students, clients or even simple users in order to produce a virtuous circle that push them towards different goals through fun [13]. But what is "fun"? The first time the authors tried to answer this question it seemed logical to associate fun with laughter. I laugh so I enjoy myself. Leaving aside that the assumption can be valid, unless the laugher does not do it bitterly, is it fair to say that this is the only case in which the entertainment finds its most complete definition? Laughing can be a result, but the way in which it has been achieved is not easily pigeonholed. For example, there are different types of comedy, yet not everyone makes people laugh or more precisely not everyone laughs at the same jokes. But something "funny" is engaging in every part of it, and involvement does not automatically presume to laugh. An event, an activity can be engaging, committing, in some ways stealing our attention and inducing us to carry it out for pleasure and satisfaction. The "Fun in workspace" has been a subject of study for many years: it analyzes and includes the positive effects of fun especially in the workplace [14][15] and its introduction in relaxation spaces of workplaces. IBM encouraged employees to try "playrooms" [13][16], and the places of relaxation have been introduced in the past as well as recently in major corporates' buildings. As evidenced by the research collected in "work hard play hard", numerous studies have been carried out revealing the positive effects of "fun at work", where they simply talk about the relaxed working environment but not yet about the integration of fun in the execution of work itself, thus suggesting that today we are at the evolution of the role of fun at its last stage. The "play" today is the basis of study following the fun, where it is necessary to understand how to exploit its positive potential by applying it to other contexts, to obtain 
benefit and satisfaction in necessary activities that do not intrinsically have the potential of play. Gamification thus appears as an application of these studies.

In the literature there are several cases of large companies that have applied gamification to their own internal training services.

IBM applied gamification in the context of an experiment involving 206 employees, using a web-based application with the aim of verifying the effect of points, badges and leaderboards on employee performance [6]. Gamification has been applied to three fundamental directives: employee engagement in company processes; promoting their social behavior in the company; support to learning performance. The authors report that the experiment results "provide strong evidence of how a gamified experience can favor learning and social behavior in employees" [6, p. 346].

Deloitte, the largest multinational professional services network, found that its employees were scarcely interested in the training programs promoted by the enterprise: therefore, the company decided to apply gamification to the executives training program [5][17]. In the digital training program, called Deloitte Leadership Academy, mechanics with points, badges and leaderboards were added. The leaderboards reset every week to allow executives with less time availability to compete on equal terms with their colleagues, even if they could not access regularly. The gamified training program provided incentives to complete lessons and to start others. Deloitte saw a $37 \%$ increase in the number of users coming back to the portal and an increase in the completions of the company training program.

SAP, the big German multinational software corporation, launched a gamification project to increase participation in its corporate community of practice [18][19]. The adoption of points in the Sap Community Network (SCN) began in the early 2000s: at that time there was no structured gamification project, but the company found an increase in the engagement of the community by applying the mechanic of points. In 2011 the SCN curators decided to renew the gamification system applied to the community, focusing on mission-based badges, additional levels and flexible rankings. Two months after the launch the results were extraordinary: the creation of content, comments and feedback increased by $1113 \%$.

\section{Methods}

\subsection{The game element hierarchy}

As described by Werbach and Hunter [9], the elements of gamification can be arranged in a three-level pyramid structure, where the highest level is the Dynamics, which constitute the essential aspects of the gamification project. Below the dynamics there are the Mechanics, which consist of the processes chosen to carry out the action. At the lowest level there are the Components, the specific instances of dynamics and mechanics. Among the components there are, for example, badges, leaderboards, points and levels.

The integration of the three levels of gamification often produces results in terms of engagement, but just as often two fundamentals of this instrument are not suffi- 
ciently taken into account, with the risk of producing results under expectations or even negative ones [4][20][21].

The two fundamentals to be taken into due consideration are the Bartle taxonomy of player types [22] and the Self-determination theory by Deci and Ryan [23]. Another aspect that is often overlooked, but useful to be taken into account, is the inclusion of a narrative in the gamification process. In the gamification of the course Effective communication with PowerPoint the authors have attempted to apply as much as possible all these aspects in a coherent way, which concern the psychology and motivation of players, in order to get a better result in terms of engagement in the course activities, going beyond a mechanistic view of gamification based exclusively on the triad point-badges-leaderboards.

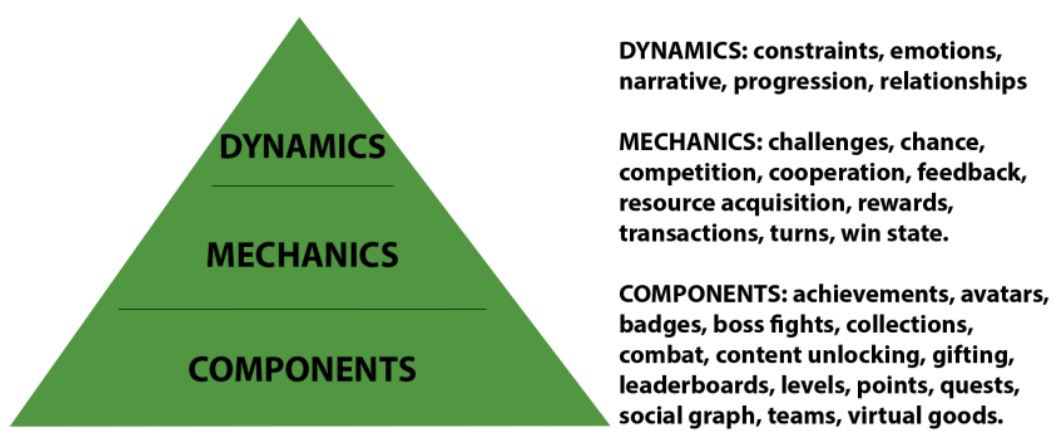

Fig. 1. Game element hierarchy by Werbach and Hunter.

\subsection{The Bartle model of player types}

In the 90's Richard Bartle studied the environment of online role-playing games (MUD - Multiuser Dungeons). He took a classification of the personalities of the players, which turned out to be valid on a universal level [22].

According to Bartle the players' personalities can be represented on the Cartesian plane: the vertical axis goes from interacting to acting; the horizontal one goes from the players to the world. Therefore, the players who want to act on the world will be the achievers: these players are hoarders and play for the pleasure of winning points, equipment, badges and in general any kind of recognition of their prestige. Those who want to interact with the world are the explorers, who derive satisfaction from the discovery: they move within the game and want to discover new places and how these places work. The explorers like environments that never cease to amaze. The players who want to interact with other players are the socializers: their maximum satisfaction consists of the continuous dialogue and relationships they establish with the other participants. Finally, there are players who like to act on other players, the killers. They play for the pleasure of imposing themselves on other players, so they look for competition and fight to crush their opponents.

Bartle's model therefore suggests that a secret of a good gamification is to create a game environment able to satisfy all the four categories. 


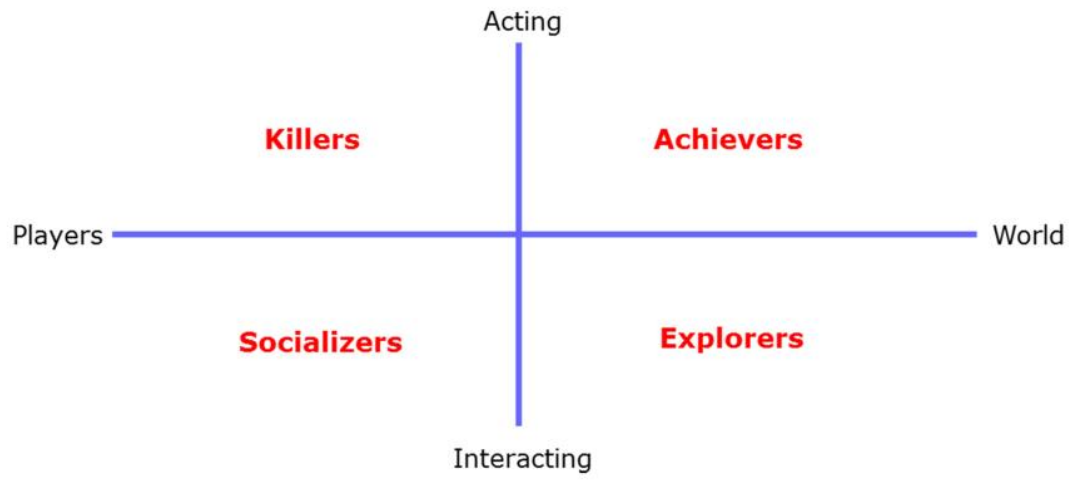

Fig. 2. Bartle model of player types

\subsection{The self-determination theory}

In the 70's two American researchers, Ed Deci and Richard Ryan, elaborated a theory of human motivation called Self-determination theory [23]. The studies on human motivation originate from the debate on the behavioral theories of empirical psychology from the 1940s to the 1960s [24]. The operant conditioning theory by B. Skinner established that all behaviors are motivated by rewards, i.e. all behaviors are acted to obtain separable consequences, such as food or money [24]. A critical reaction to the behavioral theories first led to focus on the experimental studies on animal behavior: many organisms engage in spontaneous behaviors even in the absence of reinforcement or reward, just for curiosity, play or exploration. This type of behavior was also studied in human beings [24]. Over time the researchers distinguished between two basic types of motivation: the first type, deriving from the behavioral theories, was called extrinsic motivation and refers to all the activities done to obtain a separable outcome; the second type was called intrinsic motivation and "refers to doing something because it is inherently interesting or enjoyable" [24, p.55].

Deci and Ryan therefore developed a comprehensive approach to human motivation, called Self-determination theory (SDT), which describes a motivational spectrum [25].

In the motivational spectrum of SDT, from left to right, the first element is the amotivation, i.e. the total indifference to an activity. To the right of amotivation there are four levels of extrinsic motivation. The first level is the external regulation, where the behaviors are performed to satisfy an external request or an externally imposed reward. For example, a student can do his homework just to avoid parental sanctions. The next level of extrinsic motivation is introjection: people act to obtain a lower level of social pressure or to maintain or enhance self-esteem. An example is a person smoking to get valued by his friends or peers: he smokes even if he does not want to, because doing this activity helps him to get or maintain a status among other people. 


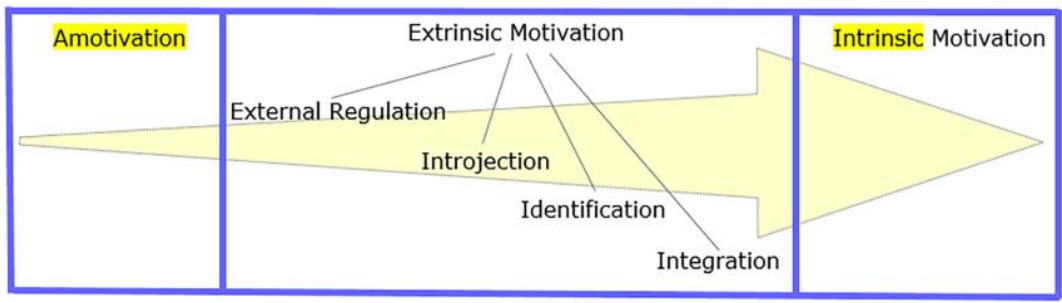

Fig. 3. Motivational spectrum of Self-determination theory by Deci and Ryan.

The identification occurs when the activity has a personal importance: this is a more self-determined form of extrinsic motivation. For example, a person could be not interested in learning math, but he knows that math is important to success in modern business, so he does it, because the activity is at least partially aligned with his personal goals. Finally, the most self-determined form of extrinsic motivation is Integration, where there is a complete alignment between the person's goals and the activity. A good example is exercise: the person wants to exercise because he knows it is good for him, so he does it, but still he does not like it because exercise is not fun. Integration is still an extrinsic motivation, since the behavior is performed for its instrumental value with respect to a goal that is separate from the behavior. The person wants to do the activity, but not because of the love of the activity itself.

The fully self-determined motivation is intrinsic motivation, at the far right of Figure 3. As stated by Deci and Ryan, intrinsically motivated activities are defined as "those that individuals find interesting and would do in the absence of operationally separable consequence" [23, p. 233]. In SDT, intrinsic motivation is enhanced by conditions that lead to psychological need satisfaction, whereas it is undermined by conditions tending to thwart need satisfaction.

Investigation of the conditions that enhance versus undermine intrinsic motivation led to find that intrinsic motivation is enhanced when three psychological needs are satisfied: competence, autonomy and relatedness [25]. Intrinsically motivated behaviors are natural and spontaneous when people feel free to follow their inner interests, so giving people autonomy, in terms of providing choice and acknowledging feelings that can enhance the sense of self-initiation, facilitates intrinsic motivation. Also, events with positive feedback that produce a sense of perceived competence in doing something, tend to facilitate intrinsic motivation. Last factor is relatedness, i.e. the situation in which the activity is connected to other people, in a context of perceived security and support: for instance, students perceive a sense of relatedness when they feel their teachers as warm and caring.

Self-determination theory therefore implies that gamification is the more effective the more the activities are directed towards intrinsic motivation.

\subsection{The octalysis framework}

Looking for another point of view about the gamification process, the authors found the Yu-kai Chou approach helpful [26]. The Octalysis framework [26, p.23] is a 
model that gives a deeper look at gamification design and it is divided into eight "core drive" in which are defined motivations. According to Chou, these motivations are what could move us into the designed experience. Specifically, they are:

1. Epic meaning \& Calling

2. Development \& Accomplishment

3. Empowerment \& Creativity \& Feedback

4. Ownership \& Possession

5. Social Influence \& Relatedness

6. Scarcity \& Impatience

7. Unpredictability \& Curiosity

8. Loss \& Avoidance. [26, pp.25-28]

What is important in these frameworks is the total "integration" with different models and theories using the core drives in various contexts. First of all, the author identifies what the authors could call two sub-frameworks where different core drives are involved: Left Brain and Right Brain, White and Black hats of Gamification. Left and Right brain is a symbolic "model" that makes a distinction between core drives considered part respectively of extrinsic and intrinsic motivation. Specifically the left brain is intended to involve logic, ownership and analytical thought, so the core drives involved are 2 (Development \& Accomplishment) , 4 (Ownership \& Possession)and 6 (Scarcity \& Impatience).The right brain is connected to creativity, curiosity and sociality, consequently to core drive 3 (Empowerment \& Creativity \& Feedback), 5 (Social Influence \& Relatedness) and 7 (Unpredictability \& Curiosity). The eight core drives are equally divided in what are considered in some way positive and negative motivations. Going further in the models adopted into Octalysis there are the White Hat and Black Hat gamification, a definition borrowed from SEO practice. Here there is a clearer distinction between "good and evil". White Hat core drive are featured by core drive 1 (Epic Meaning \& Calling); 2 (Development \& Accomplishment) and 3 ( Empowerment \& Creativity \& Feedback); Instead Black Hat is formed by core drive 6 (Scarcity \& Impatience), 7 (Unpredictability \& Curiosity) and 8 (Loss \& Avoidance). These two sub frameworks are organized with opposite motivation but however connected and necessary for a good and effective design. Positive Motivation is not necessarily motivating enough to carry out a task and vice versa. In both cases the stimuli can be considered complementary. For instance, the sense of epic that stimulates action for a noble and greater goal (Epic Meaning \& Calling) can clash with bad timing which would render the action inconclusive, due to the lack of a sense of urgency and the stress necessary to reach the goal. The sense of urgency (given by Loss \& Avoidance) therefore plays a role considered essentially negative in that it generates psychophysical stress, which however has a positive effect on the general picture, as observed in the Csikszentmihalyi flow theory [27]. According to Csikszentmihalyi, the right level of anxiety fosters the achievement of Flow state, in which the challenge and the ability to complete a task provides the necessary balance to reach the most satisfying and favorable mood for learning [28]. It therefore follows that a black hat stimulus can be used as a push towards a goal, inhibiting a procrastination continues in bringing it to completion. 


\subsection{The use of a narrative in gamification}

Some authors highlight the importance of creating a coherent narrative to increase the engagement of gamification process.

Speaking of the triad dynamics-mechanics-components, Werbach and Hunter report how "even a small dose of narration in an otherwise purely reactive environment can significantly improve engagement" [29, chapter 2 , section 3, para 4]. The same authors argue that a narration can stem from a story or from construct elements that makes the whole coherent, for instance the reference to a sport or to a corporate culture.

J. Kumar underpins that "the narrative game mechanic draws the player into a story within the game" [30. p.535], thus offering players the opportunity to express themselves through the interpretation of a role.

Another author, M. Giakalaras, argues that " Although is not crucial to have storytelling as a means for gamification is strongly recommended that we do, because it makes things much more interesting and appealing" [31, pp.5-6].

M. Coccoli, S. Iacono and G. Vercelli [32] decided to use storytelling for the realization of an online course of office automation in a university environment, which reported high completion rates.

For the gamification of the PowerPoint course discussed in this article the authors have chosen to use a story in which the action of the player take place. The player is also the protagonist and the arbitrator of the story, because getting himself to know the ending depends only on him and on how he acts within the game.

\section{The Story-Powered Gamification Model (SGM)}

The authors showed how to best use the theories and methodological approaches described in the previous paragraphs. The Octalisys method is certainly the most sophisticated, but the authors decided to emphasize the role of Story as a crucial element for the development of an effective gamification experience. The authors therefore decided to use the Game element hierarchy by Werbach \& Hunter to get an exhaustive overview of which elements can be used and how to use them in a coherent and synergistic way. Given the importance of creating a game that is satisfactory for all course participants, the authors gave the utmost importance to the use of Bartle's taxonomy, to provide elements of interest to each of the four categories of player types. Regard to the motivation to participate in the game, the authors got the game's activities as close as possible to the intrinsic motivation described by Deci and Ryan, through the three fundamental conditions: competence, autonomy and relatedness.

In our opinion, Game element hierarchy, Bartle's model of player types and Selfdetermination theory represent the three propulsive elements ("engines") of our gamification model: as a rocket launched for an interplanetary journey, the Story is the "guiding system" of the rocket to reach the targeted destination.

In figure 4 the Story guides the three engines of gamification towards the final goal of finishing the online course. Let us here outline this guiding role of Story: 
1. Have Fun in the gamified environment;

2. Reach the end of the game, by means of curiosity and focus of attention in the "driving experience" (the gamified process);

3. Maintain a high engagement through the "rolling out" of the narration plot, with the two parallel, intertwined, game and course timelines.

First, Story represents the "gaming" environment element (the "fun"), coordinating the three engines so that the course activities will be better disentangled towards the effective pedagogical objectives, i.e. avoid abandon.

Second, the Story acts as the "driving system" of the gamification process: every time we encounter a story in a movie, a book or a comic, the curiosity of knowing the story end is stimulated from the beginning to the end of the experience.

Third, the Story develops in parallel with the educational activities of the course, because the storyline is created by the actions of the participant playing a specific role within the game. It is therefore the story that guides the user towards the goal of the conclusion of the course, stimulating the curiosity to know the ending and making him responsible for the result, since knowing the ending depends exclusively on its activity in the game environment within the course.

\section{Implementation}

To develop the gamified course, the authors identified a topic related to the activities of Sky. A story was built, called The Producer: an emerging Hollywood producer is hired by a large television broadcaster to revive the fortunes of a television series in difficulty. At the beginning of the course the participant/player can choose between four series of great success with the public, but which have been closed or have had audience problems: Firefly, Lie to me, Grey's Anatomy and Last man standing [33][34][35][36].

These series have been chosen trying to range between the movie genres and preferential male or female audiences.

In the field of instructional design the authors have attempted to apply the state of the art of the recent MOOC methodologies: time, effort and objectives of the course clearly expressed in a session-based course lasting four weeks, mastery learning, short and frequent tutorials and exercises, peer assessment for exercises involving the use of PowerPoint software [37][38][39].

The development of the course, both in the instructional design and gamification field, took place wishing to combine the most recent and in-depth research with the available resources of Moodle platform [40]. In fact, It should be taken into account that this platform was born under the influence of constructivist pedagogical framework as far back in 2001 and, although it remains largely the most widely used because of its versatility and free availability, its general approach does not take into account the recent MOOCs pedagogy, nor of the possible implementation of gamification techniques. 


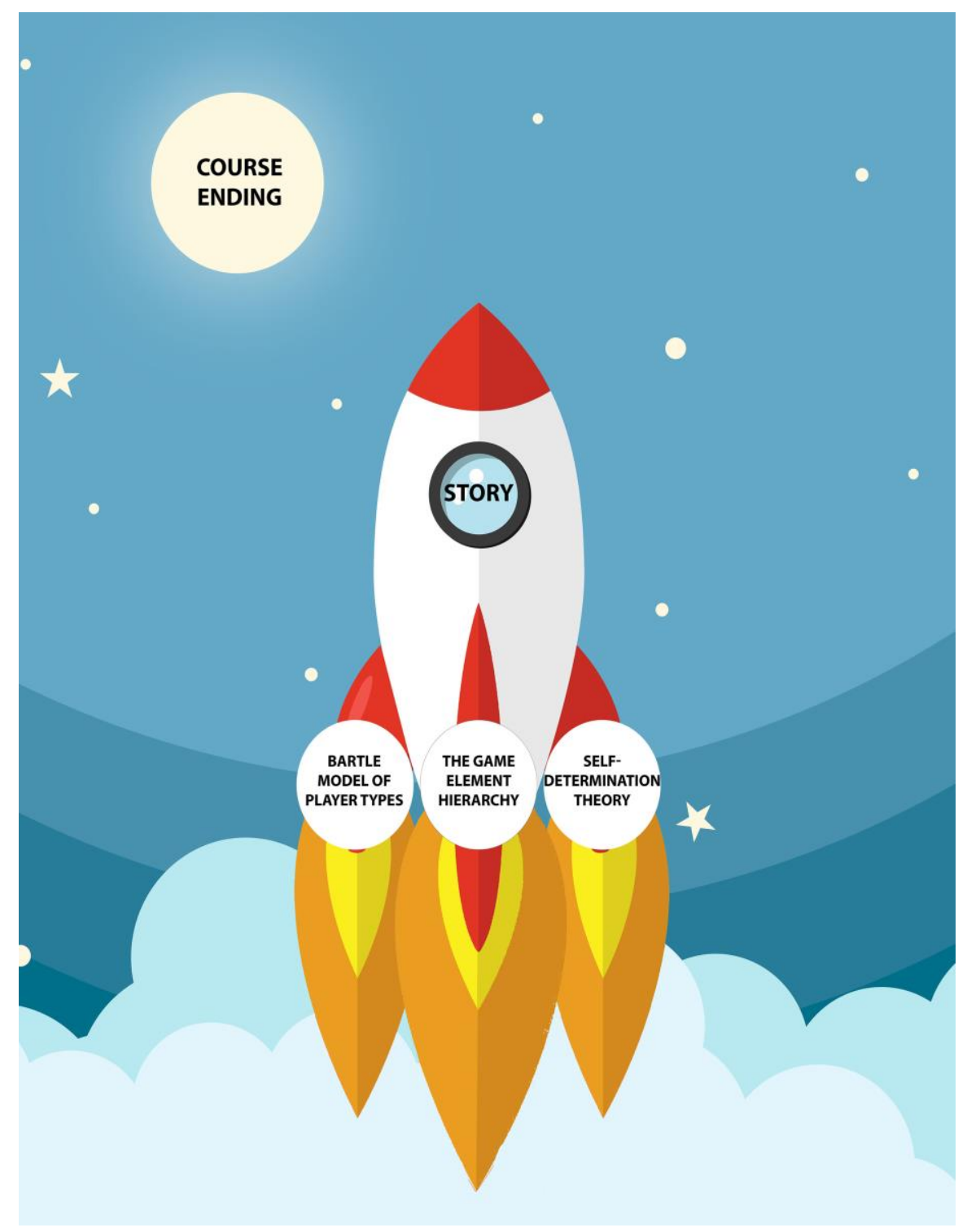

Fig. 4. Story-powered Gamification Model scheme.

Starting from the concept and the described premises, the attention was immediately directed to the search for gamification plugins that could be used in a Moodle course, keeping the game logics come accordingly. The choice was quite limited, but it allowed the use of plugins able to satisfy the four player profiles of the Bartle Model: in fact, the "Ranking" plugin is suitable for the profile of the killers, allowing them to challenge each other and fight for points. The forum, a native Moodle tool, allows socializers to satisfy their way of experiencing the game by discussing their favorite 
TV series. Finally, the use of the "Stash" plugin allowed us to establish an exchange system within the course, satisfying both achievers, who could acquire and exchange different types of items, and explorers, who thanks to the exchanges could discover new game content and the dynamics of its operation.

The game mechanics and components were therefore the consequence of the concept related to the series and the choice of available plugins. The protagonist of the game, The Producer, has the task of obtaining information on the reasons of success and critical issues of the series for which he was hired, to check if there are the necessary conditions to revive the series.

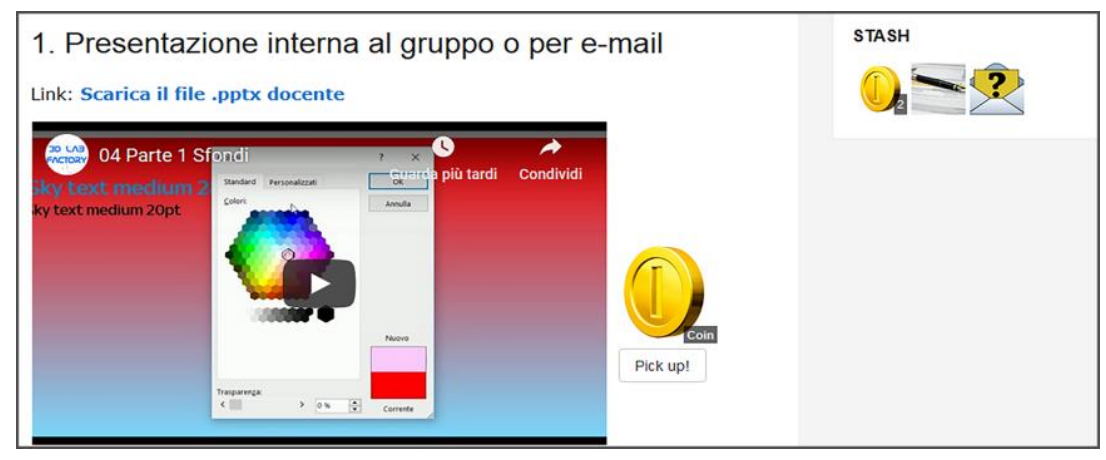

Fig. 5. Coins acquisition and count (in Italian language).

The information has a cost in coins, which the participant/The Producer can earn by carrying out the activities of the PowerPoint course. Some activities, such as tutorials and peer assessment exercises, carry coins only one time upon completion of the teaching activity, while the quizzes carry coins whenever they are passed with sufficiency. Each time the user completes an educational activity, he receives a virtual coin, counted in the stash displayed alongside the course content.

The acquired coins allow to buy information on the chosen series, in a page called "Information market". By purchasing the information, the player discovers also the "reminders" for the broadcaster's board, which are possible solutions for the crisis of the series.

The acquisition of coins and the purchase of information are intended to increase the engagement in carrying out the activities of the course. The participant/player, in fact, can see the teaching activities as functional elements to the solution of the game and can choose which and how much information to buy, as long as he is satisfied for the purpose of solving the game. The engagement given by the feeling of making aware choices is full, since arriving at the solution of the game depends entirely on the choices made by the player. Another reason of interest, especially for achievers, is the release of badges when the course user accomplishes particular conditions, such as when the course activities begin, or he discovers a certain number of information on the chosen series, or he repeats a quiz to acquire additional coins. 


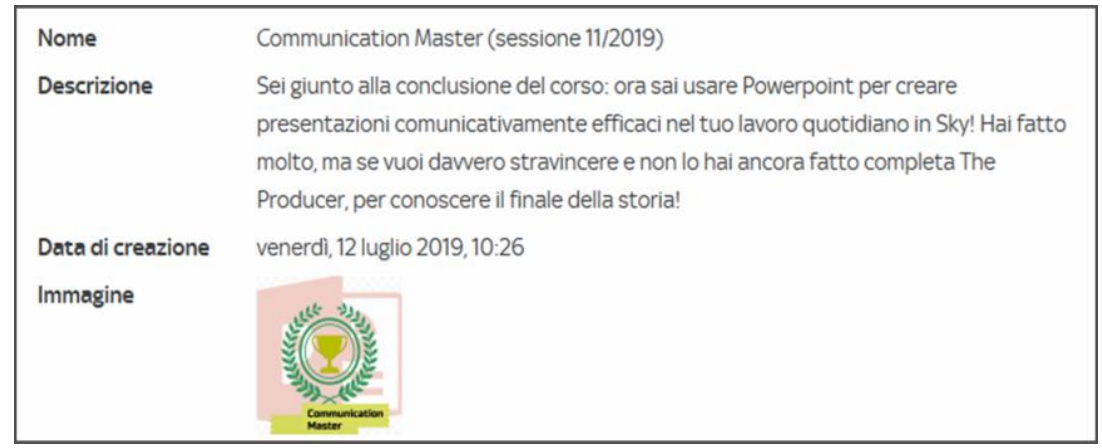

Fig. 6. Badge page (in Italian language) in the game The Producer.

Killers can satisfy their competitive nature by trying to climb the general ranking, also based on a scoring system focused on the completion of the teaching activities.

At the beginning of the last week of the course the participant visualizes the page "In front of the Board", where through the usual exchange mechanism he can trade the acquired information, if correct, to leave with his prize: the contract to realize the restart of the series. If the user has not acquired all the necessary information, he can get the coins to buy it by performing again the self-assessment tests: this allows also him to improve his knowledge of the PowerPoint software.

If the user has won the contract for the restart of the series, at the end of the last activity of the course he can read the end of the story of "The Producer": this constitutes the final reward for having carried out all the activities of the course and having identified the three necessary conditions to restart the series chosen at the beginning.

\section{Discussion}

As seen in the introduction, this work aims to contribute to the knowledge about the application of gamification to a single corporate online course, whose enrollment and completion are not mandatory, to improve the engagement of the participants.

Found in literature that, in corporate training, in many cases the conception of gamification does not go beyond the application of components such as points, levels, badges and leaderboards, the authors have applied also other theoretical knowledge and design features that could maximize the engagement of the gamified experience within a coherent general structure.

In relation to the framework developed by Werbach \& Hunter [9] the authors believe that, among the dynamics, narrative has had ample space in our work: the use of a story, in which the course user is the protagonist and arbiter, can greatly increase the engagement in the course activities, because the teaching activities focus on the development of the story and, consequently, they become lighter and more significant because related to the story. Among the mechanics there is a single, big challenge, the one that The Producer must face to revive the series in difficulty and consequently achieve the contract for its production; the elements of chance consist of the badges, 
which are given as a surprise during the game, for example when the player starts the course, or discovers all the information of the series he is playing with. Also, some mechanics are incorporated in the game: competition (through the leaderboard), resource acquisition (coins, information and final contract) and rewards, in form of badges and, above all, in form of the story end, revealed if the correct information and reminders for the board are acquired.

Finally, as components the authors used badges, collections (coins and information), content unlocking (information), a leaderboard, the points, the quest to restart the series in difficulty and finally the virtual goods of coins and acquired information, this latter graphically represented by a closed envelope.

What the authors believe it makes a difference in terms of engagement, compared to other less structured gamification experiences, regards three factors.

The first factor is the use of the Bartle model of player types: through the choice of plugins the authors have attempted to provide reasons of interest and satisfaction to all four categories of the model: achievers, explorers, socializers and killers. The authors know that is an abstraction about another type of context very specific like MUD, but the authors assumed that emotions and types of satisfaction are sufficiently generalized in these four typologies, talking about the need and satisfaction connected to challenge other people (Killers), the need to collect more clues stimulating the curiosity and maybe the will to find something wrong in the experience (Explorers and Achievers), and at the end to be involved in the experience thanks to storytelling, pushing people sharing the information with other players to know more about other "in game" tv series or to gather information they haven't collected before (Socializers). This factor should contribute to increasing the engagement in the teaching activities of the course and in its completion, having the ability to satisfy the needs of all types of players.

The second factor consists of taking account of the Self-determination theory by Deci and Ryan: the authors attempted to provide the participants/players of the course as much as possible with the intrinsic motivation of that theoretical model. The development of the story of The Producer produces a sense of competence, since activity after activity the player builds his way to get to the solution of the game and the restart of the chosen series. Also, the sense of autonomy is satisfied, since the player progresses in the game and finishes it only thanks to his own choices. In this gamification experience, therefore, two out of three conditions of Deci and Ryan's Selfdetermination theory are satisfied, feeding the intrinsic motivation of players.

Finally, the third factor is the use of a story, which holds together and coordinates dynamics, mechanics and components, the satisfaction of the tastes of each of the four categories of players and the providing of a motivation to continue the game as intrinsic as possible. An advantage of using a story is to direct the action of the course user towards the future and therefore towards the completion of the course: the participant/player carries out the teaching activities in a functional way to the development of the game, knowing that proceeding in that way will allow him, at the end of the course, to know the end of the story of which he has been the protagonist. 


\section{$7 \quad$ References}

[1] Hense, J., Klevers, M., Sailer, M., Horenburg, T., Mandl, H., \& Günthner, W. (2014). Using gamification to enhance staff motivation in logistics. In Frontiers in gaming simulation (pp. 206-213). Springer, Cham. https://doi.org/10.1007/978-3-319-04954-0_24

[2] Höglund P. (2014). Gamification in training: engagement and motivation. Thesis at Hanken School of Economics, Helsinki.

[3] Kerfoot, B. P., \& Kissane, N. (2014). The use of gamification to boost residents' engagement in simulation training. JAMA surgery, 149(11), 1208-1209. https://doi.org/10.1001/ja masurg.2014.1779

[4] Armstrong, M. B., \& Landers, R. N. (2018). Gamification of employee training and development. International Journal of Training and Development, 22(2), 162-169. https://doi. org/10.1111/ijtd.12124

[5] Huang, W. H. Y., \& Soman, D. (2013). A Practitioner's Guide to Gamification of Education. Research Report Series: Behavioural Economics in Action, Rotman School of Management, University of Toronto.

[6] Stanculescu, L. C., Bozzon, A., Sips, R. J., \& Houben, G. J. (2016). Work and play: An experiment in enterprise gamification. In Proceedings of the 19th ACM Conference on Computer-Supported Cooperative Work \& Social Computing (pp. 346-358). ACM. https:// doi.org/10.1145/2818048.2820061

[7] DuVernet, A. M., \& Popp, E. (2014). Gamification of workplace practices. The IndustrialOrganizational Psychologist, 52(1), 39-44.

[8] Sureephong, P., Dahlan, W., Chernbumroong, S., \&amp; Tongpaeng, Y. (2020). The Effect of Non-Monetary Rewards on Employee Performance in Massive Open Online Courses. International Journal Of Emerging Technologies In Learning (IJET), 15(01), pp. 88102. doi: https://doi.org/10.3991/ijet.v15i01.11470

[9] Werbach K. \& Hunter, D. (2012). For the win: how game thinking can revolutionize your business. Wharton Digital Press.

[10] Erenli, K. (2013). The Impact of Gamification - Recommending Education Scenarios. International Journal Of Emerging Technologies In Learning (IJET), 8(S1), pp. 15-21. https ://doi.org/10.3991/ijet.v8is1.2320

[11] Sobodić, A., Balaban, I., \& Kermek, D. (2018). Usability Metrics for Gamified E-learning Course: A Multilevel Approach. International Journal Of Emerging Technologies In Learning (IJET), 13(05), pp. 41-55. https://doi.org/10.3991/ijet.v13i05.8425

[12] Caponetto, I., Earp, J., \& Ott, M. (2014). Gamification and education: A literature review. In European Conference on Games Based Learning (Vol. 1, p. 50). Academic Conferences International Limited.

[13] Sümer, M., \& Aydın, C. H. (2018). Gamification in Open and Distance Learning: A Systematic Review. Learning, Design, and Technology: An International Compendium of Theory, Research, Practice, and Policy, 1-16. https://doi.org/10.1007/978-3-319-17727-4_ $\underline{115-1}$

[14] Collinson, D. (2002), “Managing humor”, Human Relations, Vol. 39 No. 3, pp. 269-288.

[15] Karl, K.A., Peluchette, J.V., Hall, L. and Harland, L. (2005), "Attitudes toward workplace fun: a three sector comparison", Journal of Leadership and Organizational Studies, Vol. 12 No. 2, pp. 1-17. https://doi.org/10.1177/107179190501200201

[16] Fluegge-Woolf, E. (2014). Play hard, work hard: Fun at work and job performance. Management Research Review, (8), 682. https://doi.org/10.1108/mrr-11-2012-0252

[17] Meister, J. C. (2013). How Deloitte made learning a game. Harvard Business Review, 2, 506-517. 
[18] Lusher, C., Case Study: Gamification at SAP Community Network. OVUM, 2013.

[19] Wenger, E. (2009). Communities of practice. Communities, 22(5).

[20] Ruhi, U. (2015). Level up your Strategy: towards a descriptive framework for meaningful enterprise gamification. Technology Innovation Management Review,5(8), 5-16. https:// doi.org/10.22215/timreview/918

[21] Turan, Z., Avinc, Z., Kara, K., \&amp; Goktas, Y. (2016). Gamification and Education: Achievements, Cognitive Loads, and Views of Students. International Journal of Emerging Technologies In Learning (IJET), 11(07), pp. 64-69. https://doi.org/10.3991/ijet.v11i07.54 $\underline{55}$

[22] Bartle, R. (1996). Hearts, clubs, diamonds, spades: Players who suit MUDs. Journal of MUD research, 1(1), 19.

[23] Deci, E. L., \& Ryan, R. M. (2000). The" what" and" why" of goal pursuits: Human needs and the self-determination of behavior. Psychological inquiry, 11(4), 227-268. https://doi. org/10.1207/s15327965pli1104_01

[24] Ryan, R. M., \& Deci, E. L. (2000a). Intrinsic and extrinsic motivations: Classic definitions and new directions. Contemporary educational psychology 25.1: 54-67. https://doi.org/10. 1006/ceps.1999.1020

[25] Ryan, R. M., \& Deci, E. L. (2000b). Self-determination theory and the facilitation of intrinsic motivation, social development, and well-being. American psychologist, 55(1), 68. https://doi.org/10.1037/0003-066x.55.1.68

[26] Chou, Y. K. (2019). Actionable gamification: Beyond points, badges, and leaderboards. Packt Publishing Ltd.

[27] Csikszentmihalyi, M., Abuhamdeh, S., \& Nakamura, J. (2014). Flow. In Flow and the foundations of positive psychology (pp. 227-238). Springer, Dordrecht. https://doi.org/10. $\underline{1007 / 978-94-017-9088-8 \quad 15}$

[28] Chen, Y., Burton, T., Vorvoreanu, M., \&amp; Whittinghill, D. (2015). Cogent: A Case Study of Meaningful Gamification in Education with Virtual Currency. International Journal Of Emerging Technologies In Learning (IJET), 10(1), pp. 39-45. https://doi.org/10.39 91/ijet.v10i1.4247

[29] Werbach, K., \& Hunter, D. (2015). The gamification toolkit: dynamics, mechanics, and components for the win [Kindle Version] Retrieved from http://www.amazon.com.

[30] Kumar J. (2013) Gamification at Work: Designing Engaging Business Software. In: Marcus A. (eds) Design, User Experience, and Usability. Health, Learning, Playing, Cultural, and Cross-Cultural User Experience. DUXU 2013. Lecture Notes in Computer Science, vol 8013. Springer, Berlin, Heidelberg. https://doi.org/10.1007/978-3-642-39241-2_58

[31] Giakalaras, M., (2016). Gamification and storytelling. University of the Aegean.

[32] Coccoli, M., Iacono, S., \& Vercelli, G. (2015). Applying gamification techniques to enhance effectiveness of video-lessons. Journal of e-Learning and Knowledge Society, 11(3).

[33] Wheadon, J. (Director), \& Edlund, B. (Producer). (2002). Firefly [Television series]. USA: Fox.

[34] Cary, A., Downer, J., \& Roth, J. (Producers). (2009). Lie to me [Television series]. USA: Fox.

[35] Shondaland team (Producer). (2005). Grey's Anatomy [Television series]. USA: American Broadcasting Company.

[36] Burditt, J. (Producer). (2011). The last man standing [Television series]. USA: American Broadcasting Company.

[37] Adamopoulos P. (2013). What makes a great mooc? An interdisciplinary analysis of student retention in online courses. In Proceedings of the 34th International Conference on Information Systems, ICIS, volume2013. 
[38] Fein A.D. (2017). Multimedia learning: principles of learning and instructional improvement in Massive, Open, Online Courses (MOOCS). PhD dissertation at University of Illinois at Urbana-Champaign.

[39] Luo, H., Robinson, A. C. \& Park, J. Y. (2014). Peer grading in a MOOC: reliability, validity, and perceived effects. Journal of Asynchronous Learning Network.

[40] Dougiamas, M., \& Taylor, P. (2003). Moodle: Using learning communities to create an open source course management system. In EdMedia+ Innovate Learning (pp. 171-178). Association for the Advancement of Computing in Education (AACE).

\section{Authors}

Saverio Iacono is a PhD Student in Digital Humanities at the University of Genova, Italy. His research interests include extended reality, game-based learning and gamification.

Mario Vallarino is research fellow at the University of Genova, Italy. His research interests include e-learning, MOOCs, gamification and virtual reality.

Gianni Vercelli is Associate Professor of UNIGE, school of Engineering. He received a master's degree in Electronic Engineering and a $\mathrm{PhD}$ in Informatics Engineering. He worked at the University of Trieste, Italy and founded TAU software house. His research interests include robotics, e-learning, medical simulation, drones and augmented reality.

Article submitted 2020-03-12. Resubmitted 2020-04-27. Final acceptance 2020-04-27. Final version published as submitted by the authors. 